\title{
Sustainable development of farm tourism in Batangas Province
}

Catapang, Efren S., Jr. $\$

Batangas State University Pablo Borbon Main Campus I, Philippines (ejaycatapang@gmail.com) Ylagan, Alex D.

Lyceum of the Philippines University - Batangas, Philippines (alexylagan04@gmail.com)

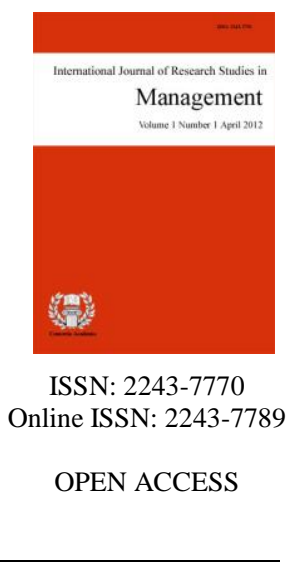

Received: 9 November 2021

Revised: 24 February 2022

Accepted: 4 March 2022 DOI: $10.5861 /$ ijrsm.2022.16

\section{Abstract}

Batangas is an agriculturally rich province in Southern Tagalog Region, a promising vehicle for long-term economic, social, cultural, and environmental progress among its people. This research identified the impact of farm tourism in the province of Batangas, both beneficial and detrimental in conjunction with sustainable development. The researcher used a descriptive research study to gather and evaluate quantitative data. A total of 385 respondents coming from the identified residents of the municipalities in Batangas province where farm tourism businesses are located comprised the sample population. In analyzing the data gathered through a survey instrument, the needed data were tallied, encoded, and interpreted using different statistical tests such as frequency, percentage distribution, weighted mean, ranking, Shapiro-Wilk Test, Mann-Whitney U test, and Kruskal Wallis test. Based on the result, majority of the respondents are Millennials, ages 25-40 years old, and single. Most are residents of the municipalities where farm tourism businesses are located and are high school graduates. The respondents moderately agreed in terms of economic and social benefits of farm tourism in Batangas Province but disagreed in terms of cultural and environmental benefits. They moderately agreed in terms of the negative economic and social impacts of farm tourism in Batangas Province but disagreed in terms of cultural and environmental impacts. Given the results, the researcher proposed an Action Plan for the Sustainable Development of Farm Tourism in Batangas Province to help the business owners and for further awareness of the residents about the significance of farm tourism in the province.

Keywords: sustainable development, farm tourism, tourism impacts, farm tourism sustainability, Batangas province farm tourism 


\section{Sustainable development of farm tourism in Batangas Province}

\section{Introduction}

The United Nations has been proclaimed in 2017 as the international year of Sustainable Tourism for Development. It was a once-in-a-lifetime opportunity for UNWTO Secretary General Taleb Rifai to promote the tourist sector's contribution to the three pillars of sustainability - economic, social, and environmental - while also raising awareness of the genuine dimensions of a sector that is frequently undervalued. According to the United Nations World Tourism Organization (UNWTO) and the United Nations Development Programme (UNDP) (2017), tourism is one of the world's fastest growing economic sectors, and a major contributor to income and employment, economic expansion, environmental conservation, and poverty alleviation. In the foreword, Achim Steiner (UNWTO and UNDP, 2017) claims that while the tourism sector can create quality jobs that promote long-term growth, alleviate poverty, and provide incentives for environmental conservation, growing the tourism industry would put further strain on ecosystems and biodiversity, on which so many residents and local areas rely.

Part of the sustainable development goals of the United Nations is tourism industry wherein farm tourism is included. Farm tourism helps to market the local community's homegrown products. It enables for economic activity and the creation of new agricultural demand. It will establish a socioeconomic for the farmers, workers, and beneficiaries of the farm with an appropriate sustainable development plan. In cooperation with the Department of Tourism will genuinely ignite the development and rehabilitation of the tourist and agriculture industries in the Philippines, which were both badly damaged by the existing pandemic, Ms. Yao said in a statement. Meanwhile, according to Ms. Puyat, the DOT Secretary, "the DOT wants to link farm tourism to sustainable agricultural practices by cooperating with FAO." The goal is to provide our farm workers and fishermen with the skills and infrastructure they need to make it through these difficult times. Farm tourism, they noted, may appeal to individuals who enjoy harvesting, feeding, and raising animals, fishing, and camping, among other activities (Ochave, 2020).

As far as Batangas Province is concerned, the province was recognized as a competitive province. There are several farms and ranches that are ideal for leisure activities. These farm tourism sites offered tours that allow visitors to see the growing, harvesting, and processing of locally cultivated goods. (Festijo, et al., 2019). Farm tourism is positive social impacts were also identified such as creates a positive image of the countryside, gives recreational possibilities for inhabitants and visitors, aids in the modernizing process, and provides chances for further education nevertheless its negative social impacts include the creation of anger and animosity as a result of significant financial disparities, moral degradation leading to increased crime, prostitution, and social disputes, and conflicts in traditional communities and beliefs. Furthermore, farm tourism has a positive cultural impact by encouraging pride in local arts, crafts, and cultural expression, as well as the preservation of cultural heritage, whereas negative cultural impacts include the loss of spiritual and cultural sense because of excessive globalization and product commercialization, giving up indigenous culture in favor of adapting to modern, commonly accepted standards.

On the other hand, farm tourism has a detrimental impact to the society but there is a beneficial impact as well. These were being identified in the study of Petrovic, et al., (2017) that farm tourism being part of agritourism has positive economic impact wherein it creates job possibilities in rural regions. Farm tourism produces foreign exchange supplies, increases income and the gross domestic product (GDP) (GNP) and improvement of the infrastructure, amenities, and services in rural areas while the negative impacts are causes inflation of land value, food and other product prices are being raised and seasonal work is common. In this challenging time, the study fills the gap by establishing the community awareness and social orientations on the sustainability of farm tourism in Batangas province. It also determines the benefits of farm tourism as well as the 
challenges that is detrimental in farm tourism sustainability in terms of economic, social, cultural, and environmental aspect. Based on the results, the researcher proposes actions plan that could help farm tourism in Batangas Province sustainable and reliant. This research study will be beneficial to the community from the nearby areas where Farm Tourism businesses are located. Their awareness of the business will be enhanced, employment, social interactions with different people, cultural exchange and environmentally friendly. Also, it is beneficial to the farm tourism business owners in terms of marketing and promotions. The future researcher can utilize this study for further enhancement and validation of the gathered data.

\subsection{Objectives of the Study}

This research aimed to assess the sustainable development of farm tourism in Batangas Province. Specifically, it aimed to: describe the profile of respondents in terms of age, sex, civil status, education, types of respondents and the location of farm tourism; assess the beneficial impact of farm tourism in Batangas province as perceived by the residents/business owners in terms of: Economic, Social, Cultural and Environmental; determine the detrimental impacts of farm tourism in Batangas province as perceived by the residents/business owners in terms of: Economic, Social, Cultural and Environmental; test the significant difference when group according to the profile variable.

\section{Method}

Research Design - This descriptive research presented the data collected which pertains to the sustainability of Farm Tourism in Batangas Province. Further, the researcher used quantitative research to confirm the hypotheses of the study. According to Bhandari (2020), Quantitative research is the process of collecting and analyzing numerical data. It may be used to look for patterns and averages, make predictions, evaluate causal linkages, and extrapolate results to larger groups.

Participants of the Study - The researcher identified the selected farm tourism sites in Batangas Province where local the residents near the area and its Barangay Officials will serve as respondents of the study. The Department of Tourism (DOT) Accredited Farm Tourism specifically located or situated in the municipality of Bauan, Alitagtag, San Jose, Rosario, Taal, Laurel and Mataas na Kahoy. For the respondents, they must be at least familiar or have an experience in visiting the farm tourism sites located on the abovementioned municipalities. A total of 385 people took part in the survey with an effect size of 0.25 , a power probability of 0.95 and an alpha level of 0.05 using $G^{*}$ Power 3.1.9. The researcher used the simple random sampling techniques, survey questionnaire, interview, and observations among the selected respondents of the study.

Data Gathering Instrument - The researcher used modified questionnaire. The researcher adapted the survey questionnaire from various studies of Kim (2002) entitled "The Effects of Tourism Impacts upon Quality of Life of Residents in the Community and Taloza, (2020) entitled, "Tourism in the heritage city of Vigan: Basis for Sustainable Development", anchored to the theory cited by the researcher like the impact of farm tourism in Batangas province, which is divided into three (3) parts: Part I focused to the demographic profile of the respondents; Part II assessed the beneficial impact of farm tourism in Batangas province; and Part III determined the detrimental impact of farm tourism in Batangas province. Cronbach's alpha (also known as coefficient alpha) is a measure of internal consistency, or how closely a group of items is connected. It is regarded as a scale reliability measure. It is shown that Cronbach's reliability estimates for all four sub-dimensions of sustainability in the beneficial impact of farm tourism in Batangas Province in terms of economic with scoring of 0.895 which is Good, social with 0.848 which is also good, cultural with 0.906 which is excellent and environmental with 0.877 which is also good. While, in the detrimental impact of farm tourism in Batangas Province in terms of economic with scoring of 0.845 which is good, social with 0.947 which is excellent, cultural with 0.955 , excellent and environmental with scoring of 0.911 , also excellent.

Data Gathering Procedure - The researcher prepared for the distribution of the survey questionnaire after 
establishing the desired respondents. The researcher conducted observation and interview among the respondents in selected farm tourism sites in Batangas province. The researcher visited the selected municipalities personally and followed the COVID-19 health and safety protocol implemented by the Inter-Agency Task Force for the Management of Emerging Infectious Diseases (IATF).

Data Analysis - The following statistical tools were used to conduct data analysis. The demographic profile of the respondents was described using frequency and percentage distribution. The beneficial and detrimental impacts of farm tourism in Batangas Province were assessed using weighted averages and ranking. The Shapiro-Wilk Test found that two key variables' p-values are less than 0.05 , indicating that the data set is not regularly distributed. To assess significant differences, the non-parametric tests Mann-Whitney U test for two groups and Kruskal Wallis test for three groups were employed. The factors were assessed using the following Likert Scale: 4.50 - 5.00 - Strongly Agree; 3.50 - 4.49 - Agree; 2.50 - 3.49 - Moderately Agree; 1.50 - 2.49 Disagree; 1.00 - 1.49 - Strongly Disagree. Furthermore, all data were handled with PASW version 26 statistical software to better understand the study's results using an alpha level of 0.05 .

Ethical Consideration - The researcher assured that the ethical considerations were established before the conduct of the study. The researcher asked permission to the author for using and modifying the questionnaire before distributing it to the respondents. The researcher fully briefed all the respondents regarding the purpose of this research and secured consent letter duly signed or approved by the respondents. The researcher explained clearly to the respondents that their participation in this research is voluntary. The research data collection procedures and data analysis described clearly to the respondents. The researcher ensured that data collected or gathered maintained the highest confidentiality of information given by the respondents as well as by protecting their anonymity in compliance to data privacy act of the Philippines. Lastly, the researcher ensured that the status of the respondents in terms of answering the survey questionnaire was not affected or put into jeopardy.

\section{Results and Discussion}

\section{Table 1}

Profile of the Respondents

\begin{tabular}{|c|c|c|}
\hline Age & Frequency & Percentage \\
\hline Gen Z (18-24 y/o) & 58 & 15.10 \\
\hline Millennials (25-40 y/o) & 178 & 46.20 \\
\hline Gen $X(41-56$ y/o $)$ & 115 & 29.90 \\
\hline Boomers (57-75 y/o) & 34 & 8.80 \\
\hline \multicolumn{3}{|l|}{ Sex } \\
\hline Male & 195 & 50.60 \\
\hline Female & 190 & 49.40 \\
\hline \multicolumn{3}{|l|}{ Civil Status } \\
\hline Single & 172 & 44.7 \\
\hline Married & 213 & 55.3 \\
\hline \multicolumn{3}{|l|}{ Education } \\
\hline Graduate Program & 6 & 1.6 \\
\hline Undergraduate Program & 88 & 22.9 \\
\hline Vocational Course & 57 & 14.8 \\
\hline High School & 234 & 60.8 \\
\hline \multicolumn{3}{|l|}{ Types of Respondents } \\
\hline Farm Tourism Owner & 2 & 0.5 \\
\hline Farm Tourism Employee & 35 & 9.1 \\
\hline Local Residents & 348 & 90.4 \\
\hline \multicolumn{3}{|l|}{ Location of Farm Tourism } \\
\hline Bauan, Batangas & 73 & 19 \\
\hline Alitagtag, Batangas & 22 & 5.7 \\
\hline San Jose, Batangas & 72 & 18.7 \\
\hline Rosario, Batangas & 103 & 26.8 \\
\hline
\end{tabular}

94 Consortia Academia Publishing (A Partner of Tourism Educators and Movers of the Philippines) 
Sustainable development of farm tourism in Batangas Province

\begin{tabular}{lll} 
Taal, Batangas & 50 & 13 \\
Laurel, Batangas & 36 & 9.4 \\
Mataas na kahoy, Batangas & 29 & 7.5 \\
\hline
\end{tabular}

It can be observed from the table that less than half of the respondents were Millennials (25-40 y/o) which comprised $46.20 \%$ or having a frequency of 178 . It is followed by those who belong to Gen X (41 to 56 y/o) which constitute $29.90 \%$ of the respondents. The least number of respondents were Boomers (56 to $75 \mathrm{y} / \mathrm{o}$ ) which is $8.80 \%$ of them or a frequency of 34 . Most of the respondents are millennials because they are the easiest to approach among others as the researcher distribute the survey questionnaire in every municipality where farm tourism is located. The respondents were eager to share their opinion with enthusiasm for travel and tourism. It is stated in the study of Rebollo (2018) that the millennial generation is the most recent to enter the tourism industry, and they are now active travelers who are shaping travel tastes, setting trends, encouraging others, and influencing people's attitudes and behaviors. They have comparable experiences, but when it comes to behaviour, attitudes, intentions, beliefs, and lifestyles, they have distinct likes and lifestyles. Furthermore, research revealed that Millennials are quickly becoming one of the most important customers for the tourism and travel industry. As a result, tourism locations have had to rethink their marketing techniques to appeal to this demographic (Leake, 2018).

In terms of sex, there were almost equal number of female and male respondents in this study, though more than half are male with a frequency of 195 or comprising $50.60 \%$ of the respondents. In addition, most of them are married with a frequency of 213 or $55.3 \%$ while the rest were single. It is observed that the number of respondents is almost equal and most of them were male respondents. Both male and female have the interest in travel and tourism but since agriculture and farming is involved, it is obvious that this type of profession is common to male in Batangas province. According to Kara and Mkwizu (2020), gender is one of the most critical factors influencing travel demand. Depending on their motivations for traveling, men and women travel in various ways. Men are more likely than women to travel. Men travel for business, but women go to meet friends and family and prefer shorter-distance excursions than men. Furthermore, in the article written by Ani and Cassola (2020) in terms of equal access to social and economic opportunities, history shows that women have historically taken a backseat. This is true even in the agricultural sector, with various reports and research demonstrating that Philippine agriculture has always been dominated by men.

In terms of civil status, most of the respondents are married and majority are in the millennial age. This is the ideal age to get married before they reach the age backet of the Generation X. On the other hand, the Philippine Statistic Authority (2021) has the record of married people in Batangas province in the year 2019, and it is stated that most of them were married at the age of 25-29 years old which is in the age bracket of Millennial generation. Based on the respondents' education, majority reached High school with a frequency of 234 or $60.8 \%$ while the least number of respondents were in the Graduate Program which comprised $1.6 \%$ or having a frequency of 6 . Residential is the area where the farm tourism businesses are located, and the farmers are less fortunate and underprivileged to take bachelor programs and only finished secondary education.

To father testify the above statement, it is stated in the records of the Philippine Statistics Authority that in 2017, out-of-school youth (OSYs) made up 9\% of the estimated 39.2 million Filipinos aged 6 to 24 years old. 83.1 percent of those polled were between the ages of 16 and 24, 11.2 percent were aged 12 to 15 , and 5.7 percent were aged 6 to 11. According to the PSA statistics, the most common reasons for OSYs not attending school were marriage or family duties, a lack of personal motivation, and the high cost of education or financial concerns. Around half of OSYs come from families with per capita incomes that place them in the lowest third of the population (PSA, 2018).

In contrary, number of respondents who attended graduate school are few because they don't have enough financial resources. Also, most of the people who take graduate school programs were involved in academe and not with other profession specifically in agriculture. According to Shellhouse, et al. (2020), most people who attended Graduate School programs were affiliated with academic institutions for the purpose of institutional 
requirements and program rigor.

Based on the types, largest portion of the respondents are local residents at $90.4 \%$ and with a frequency of 348. There are also a few who were Farm Tourism employee which is $9.1 \%$ of the respondents or having a frequency of 35 . Only two of them are Local Farm owners at $0.5 \%$. Most number of the respondents are local residents of the municipalities where farm tourism sites are located because the survey questionnaire is intended for them to test if farm tourism in their areas can help the community to boost their economy, good social interaction with the tourist, cultural exchange, and promotions of environmental awareness. According to Gabor (2016), farm tourism is a great example of inclusive growth for local communities in terms of socio - economic status, cultural and environmental. However, farm tourism business owners and employees have few respondents because the answer might be based to the beneficial impact of farm tourism business and few employees were affiliated with the business due to the current situation. Unlike other tourism and hospitality businesses such as hotels and resorts, there are few farm tourism sites in the province. In the statement of the tourism office of Batangas province or Rich Batangas (2021), only seven farm tourism business are part of Batangas Alliance for Farm Tourism Destinations with compliance to Department of Tourism which supports the Republic Act No. 10816 regarding the Development and Promotion of Farm Tourism in the Philippines.

Lastly, in terms of location of farm tourism, more than a quarter of the respondents were from Rosario, Batangas which constitute $26.85 \%$ while $19 \%$ were from Bauan, Batangas. The least number of respondents were in Alitagtag, Batangas which is $5.7 \%$ of the total. The results revealed that the number respondents vary from the number of populations in the municipality wherein the leading municipality in terms of its population volume is from the municipality of Rosario, Batangas with one hundred twenty - nine thousand four hundred seven $(129,407)$ total number of populations, followed by Bauan Batangas with ninety - one thousand two hundred forty - one $(91,241)$ total number of populations. While in the case of Alitagtag, Batangas has the least number of populations among all the municipalities with twenty - seven thousand seven hundred thirty $(27,730)$ total number of population where the farm tourism businesses are found in the province of Batangas.

Table 2

Assessment in Beneficial Impact of Farm Tourism in Batangas Province

\begin{tabular}{lcc}
\hline \multicolumn{1}{c}{ Indicators } & Composite Mean & VI \\
\hline Economic & 3.58 & Agree \\
Social & 3.47 & Moderately Agree \\
Cultural & 3.46 & Moderately Agree \\
Environmental & 3.46 & Moderately Agree \\
Over-all Mean & 3.49 & Moderately Agree \\
\hline Legend: $4.50-5.00-$ Strongly Agree; $3.50-4.49-$ Agree; $2.50-3.49-$ Moderately Agree; $1.50-2.49-$ Disagree; $1.00-1.49-$ Strongly
\end{tabular}

The overall respondents, moderately agreed on the beneficial impacts of farm tourism in Batangas province with the highest assessment in terms of economic with a composite mean of 3.58 which the only indicator which the respondents agreed upon. It was followed by the beneficial impacts in terms of social at 3.47 weighted mean while assessments on the cultural and environmental impacts have the same composite mean of 3.46, the three among which were moderately agreed upon by the respondents. The resident Batangas province as the main respondent of the study agreed that farm tourism has an economic benefit to most of them because it is being observed that residents were given a chance to be part of the business as an employee and transportation sectors like public utility vehicles and small business enterprises which sells local products were gaining benefit due to the demand of the tourist arrival in the area resulting to the increase level of economy of Batangas province. According to the study conducted by Festijo, et al., (2019), Batangas contributes the most regional income from the agriculture sector in Region IV - A. The growth of Agritourism Enterprises is one of the economic-based industries in which the province is reasonably efficient.

It is observed also by the respondents that it moderately increases the social awareness of people through farm tourism. The residents are somehow aware with benefits of social impact of farm tourism in the area. Farm 
tourism has numerous social benefits that demonstrate beneficial societal impacts like strengthening communities and providing social services as an example. Farming benefits participants' health and well-being in a variety of ways, including increased social skills as they interact with others. Farm family and visitors has greater self-confidence, willingness to try new things, meet new people, make friends, personal responsibility, and addressing social exclusion by integrating people (Social Farming Ireland, 2019).

On the other hand, respondents moderately agreed with the beneficial impact of Farm tourism in terms of cultural and environmental. Batanguenios do not agree much in terms of cultural exchange because they are not easily influenced by nearby provinces and the National Capital Region which is said to be the most influential city in the Philippines. Moreover, it is said that the strong presence of Tagalog culture is clearly visible to the present day even most of the residents have dealt with different cultures and lifestyle (Province of Batangas Official Website, 2021).

In terms of environmental aspect, it is stated in the Cities and Municipalities Competitive Index (CMCI) of Batangas province (2020), three of the municipalities where the farm tourism sites can be found are categorized as the first-class municipalities such as Bauan, Rosario and San Jose which are highly urbanized with the presence of air, noise, and crowd pollution. Followed by Laurel and Taal as the third-class municipalities and lastly, Mataas na Kahoy and Alitagtag were considered as the fourth-class municipalities, where there is a presence of noise and air pollution due to the drastic development or urbanization.

Table 3

Assessment in Detrimental Impact of Farm Tourism in Batangas Province

\begin{tabular}{l|ccc}
\hline Indicators & Composite Mean & VI & Rank \\
\hline Economic & 2.66 & Moderately Agree & 1 \\
Social & 2.50 & Moderately Agree & 2 \\
Cultural & 2.46 & Disagree & 3 \\
Environmental & 2.33 & Disagree & 4 \\
\hline Over-all Mean & 2.49 & Disagree & \\
\hline
\end{tabular}

Legend: 4.50 - 5.00 -Strongly Agree;3.50 - 4.49 - Agree; 2.50 - 3.49 - Moderately Agree; 1.50 - 2.49 - Disagree; 1.00 - 1.49 - Strongly

Respondents generally disagreed on the detrimental impact of farm tourism in Batangas Province as indicated by the over-all mean of 2.49. The highest assessment was accounted to detrimental impacts in terms of economic with 2.66 composite mean, followed by assessment in terms of social with a composite mean of 2.50 which were both moderately agreed upon by the respondents. However, respondents disagreed on the detrimental impacts of farm tourism in terms of cultural with the composite means of 2.46 and environmental with 2.33, accordingly. Most of the respondents moderately agreed that farm tourism has a detrimental impact in terms of economic. They see it as an opportunity and a threat in different way in contrary. Furthermore, in the research conducted by An, et al. (2021), communities' perceptions of economic benefits were shown to be one of the most powerful elements in predicting residents' attitudes toward tourist development in previous studies. These perceived tourist impacts such as favorable and negative. Increased career prospects, pay increases, improved infrastructure, and improved living conditions are among the positive categories. The negative category is mostly concerned with rising living costs.

On the other hand, the respondents disagreed that farm tourism has detrimental impact to the environment. They have this level of awareness that the main purpose of farm tourism is promote environmental awareness aligned with the sustainable development goal (SDG) of the United Nation. A responsible and sustainable kind of farm tourism is environmental sustainability. Ecotourism is generated through ecologically friendly farming and agribusiness methods that focus on environmental sustainability. Environmental sustainability guarantees that we can live comfortably while meeting our demands and practicing waste management. Sustainable agritourism involves recreational activities that do not harm the environment or drain finite resources (Tseng, et al., 2019). 
Catapang, Efren S., Jr., \& Ylagan, A. D.

\section{Table 4}

Differences in Assessment in Beneficial and Detrimental Impact when grouped to Profile Variables

\begin{tabular}{|c|c|c|c|}
\hline Age & $\mathrm{U} / \lambda 2 \mathrm{c}$ & $\mathrm{p}$-value & Interpretation \\
\hline \multicolumn{4}{|c|}{ Beneficial Impact } \\
\hline Economic & 4.543 & 0.208 & Not Significant \\
\hline Social & 6.110 & 0.106 & Not Significant \\
\hline Cultural & 2.150 & 0.542 & Not Significant \\
\hline Environmental & 0.590 & 0.899 & Not Significant \\
\hline \multicolumn{4}{|c|}{ Detrimental Impact } \\
\hline Economic & 25.855 & $<0.001$ & Significant \\
\hline Social & 17.535 & 0.001 & Significant \\
\hline Cultural & 15.558 & 0.001 & Significant \\
\hline Environmental & 9.895 & 0.019 & Significant \\
\hline \multicolumn{4}{|l|}{ Sex } \\
\hline \multicolumn{4}{|c|}{ Beneficial Impact } \\
\hline Economic & 18081.5 & 0.684 & Not Significant \\
\hline Social & 17787.0 & 0.553 & Not Significant \\
\hline Cultural & 17778.5 & 0.548 & Not Significant \\
\hline Environmental & 18399.0 & 0.977 & Not Significant \\
\hline \multicolumn{4}{|c|}{ Detrimental Impact } \\
\hline Economic & 16127.5 & 0.034 & Significant \\
\hline Social & 17147.5 & 0.238 & Not Significant \\
\hline Cultural & 17977.5 & 0.677 & Not Significant \\
\hline Environmental & 18107.5 & 0.766 & Not Significant \\
\hline \multicolumn{4}{|l|}{ Civil Status } \\
\hline \multicolumn{4}{|l|}{ Beneficial Impact } \\
\hline Economic & 17127.0 & 0.272 & Not Significant \\
\hline Social & 16076.5 & 0.046 & Significant \\
\hline Cultural & 17057.0 & 0.276 & Not Significant \\
\hline Environmental & 18147.0 & 0.937 & Not Significant \\
\hline \multicolumn{4}{|c|}{ Detrimental Impact } \\
\hline Economic & 16580.0 & 0.126 & Not Significant \\
\hline Social & 17983.5 & 0.818 & Not Significant \\
\hline Cultural & 17635.0 & 0.580 & Not Significant \\
\hline Environmental & 17928.0 & 0.778 & Not Significant \\
\hline Education & $\mathrm{U} / \lambda 2 \mathrm{c}$ & p-value & Interpretation \\
\hline \multicolumn{4}{|c|}{ Beneficial Impact } \\
\hline Economic & 64.437 & $<0.001$ & Significant \\
\hline Social & 44.109 & $<0.001$ & Significant \\
\hline Cultural & 52.057 & $<0.001$ & Significant \\
\hline Environmental & 37.897 & $<0.001$ & Significant \\
\hline \multicolumn{4}{|c|}{ Detrimental Impact } \\
\hline Economic & 8.836 & 0.032 & Significant \\
\hline Social & 25.932 & $<0.001$ & Significant \\
\hline Cultural & 30.537 & $<0.001$ & Significant \\
\hline Environmental & 25.713 & $<0.001$ & Significant \\
\hline \multicolumn{4}{|c|}{ Types of Respondents } \\
\hline \multicolumn{4}{|c|}{ Beneficial Impact } \\
\hline Economic & 5.504 & 0.064 & Not Significant \\
\hline
\end{tabular}

98 Consortia Academia Publishing (A Partner of Tourism Educators and Movers of the Philippines) 
Sustainable development of farm tourism in Batangas Province

\begin{tabular}{|c|c|c|c|}
\hline Social & 5.238 & 0.073 & Not Significant \\
\hline Cultural & 4.956 & 0.084 & Not Significant \\
\hline Environmental & 3.991 & 0.136 & Not Significant \\
\hline \multicolumn{4}{|c|}{ Detrimental Impact } \\
\hline Economic & 6.079 & 0.048 & Significant \\
\hline Social & 0.712 & 0.700 & Not Significant \\
\hline Cultural & 0.233 & 0.890 & Not Significant \\
\hline Environmental & 4.476 & 0.107 & Not Significant \\
\hline \multicolumn{4}{|c|}{ Location of Farm Tourism } \\
\hline \multicolumn{4}{|c|}{ Beneficial Impact } \\
\hline Economic & 82.038 & $<0.001$ & Significant \\
\hline Social & 63.389 & $<0.001$ & Significant \\
\hline Cultural & 63.389 & $<0.001$ & Significant \\
\hline Environmental & 76.720 & $<0.001$ & Significant \\
\hline \multicolumn{4}{|c|}{ Detrimental Impact } \\
\hline Economic & 78.257 & $<0.001$ & Significant \\
\hline Social & 148.905 & $<0.001$ & Significant \\
\hline Cultural & 162.057 & $<0.001$ & Significant \\
\hline Environmental & 168.955 & $<0.001$ & Significant \\
\hline
\end{tabular}

Legend: Significant at p-value $<0.05$;

As indicated from the results above, there is significant difference in assessment in detrimental impact of farm tourism in terms of economic, social, cultural, and environmental when grouped to age since the computed $\mathrm{p}$ values are less than 0.05 level of significance. Thus, assessment in detrimental impact of farm tourism in terms of economic, social, cultural, and environmental differs when grouped to age. Millennial respondents (25-40 y/o) had higher assessment in detrimental impact of farm tourism in terms of economic, social, cultural, and environmental. It is observed by the respondents that they were affected by the inflation rate in the year 2021 and most businesses was affected by the crisis. They think that if they increase the price, they are going to survive the current situation.

Batangas province ranked second in experiencing faster growth of inflation rates in August 2021 in the entire CALABARZON region with an increase of 1.5 percent index points (Philippine Statistic Authority, 2021). Furthermore, it is indicated in the study of Buted, Bonsol, Ilagan, Lacorte, Ona, and Mendoza (2018), the province of Batangas' economy has continued to grow because of the abundance of industrialization brought about by a good economic climate and strategic position, both of which are key factors in advancement. Meanwhile in terms social impact, most of the respondents moderately agreed and has the lowest assessment that the farm tourism contributes to the value distortion among the youth. Residents believed that a shift in local attitudes toward tourists is one of the social repercussions of growing tourist numbers. It is revealed in the study of Szromek, et al. (2019) that the way communities see tourism's good and negative repercussions determines this transition. Locals' social carrying capacity restrictions, or their ability to bear changes as they occur, have resulted in the creation of a hostile attitude toward tourists.

Traditional social life has changed significantly at some World Heritage sites because of the tourism industry's ongoing development. Furthermore, many rural people's opinions have shifted irreversibly as a result of the growing reliance of many regions' economies on tourism. One example of these transformations is the impact of tourism growth and its economic efficiency on people' traditional beliefs, lifestyles, and interpersonal interactions in historic villages classified as World Heritage Sites (Zhuang, et al., 2019). Lastly, in terms of environmental aspect, farm tourism does not directly contribute to sewage and solid waste contamination, according to residents, farm tourism proprietors, and its employees. For the goal of environmental preservation and sustainable tourism, the government has enacted Republic Act 9003 Ecological Solid Waste Management 
Act, which the Department of Tourism has adopted to every tourism enterprise.

In general, research reveals that farm tourism in connection with rural tourism has a significant difference in terms of age. They have different views regarding what might be the possible negative impact of the business in terms of economic, social, cultural, and environmental. According to the study of Sharmin, et al. (2020), the millennials are the generation after the baby boomers and generation X. They range in age from 25 to 40 years old. According to generational theory, establishing a collective vision held by members of the millennial generation includes individuals born between 1980 and 2000 and entered young adulthood around the beginning of 21 st century. Furthermore, due to technical, socio-cultural, and economic variables, millennials have different views, beliefs, and behaviors than prior generations.

There is significant difference in assessment in detrimental impact of farm tourism in terms of economic when grouped to sex and type of respondents since the computed p values is less than 0.05 level of significance. Therefore, assessment in detrimental impact of farm tourism in terms of economic varies when grouped to sex and type of respondents. Male respondents had higher assessment in detrimental impact of farm tourism in terms of economic. It is observed by the male respondents who reside in the municipality where farm tourism businesses are in Batangas province that somehow farm tourism is viewed and moderately agreed that it has a negative economic impact because it can increase the cost of living in the community.

As a result, males as the head of the family and provider are concerned about what may happen if the community's cost of living increases. It would be a problem for them what to feed for their families using their daily earnings at work and particularly farmers who receive less attention from the government and get less compensations and benefits than any other jobs in the country. In the study conducted by Retnowulandari (2018), men are progressively taking on key responsibilities in the family, first as active fathers, and then as full participants. As discussed previously, many research revealed that most farmers are male and farmers are underprivilege in the Philippines. According to the Philippine Statistics Authority (PSA), farmers remain one of the poorest sectors in the country, with the greatest poverty incidence of 34.3 percent in 2015. This stems from their ongoing anxiety about rising farming costs and low yields (National Anti-Poverty Commission, 2019).

Furthermore, the gender has a vital role in sustainability of farm tourism. Agritourism's success is heavily influenced by the gender of workers and their degrees of motivation. Females are more motivated to participate in agritourism than males, according to several researchers. Female agritourism business owners, for example, are more likely than their male counterparts to provide a variety of health and souvenir items. As a result, most male respondents place a larger value on the negative economic impact of agricultural tourism (Bhatta and Ohe, 2020). It is also stated in the Philippine Statistics Authority (2021) that Batangas province ranked second in the entire CALABARZON region in terms of faster inflation rates in August 2021, with an increase of 1.5 percent index points, compared with Quezon province, which went from 5.5 percent in July 2021 to 7.5 percent in August 2021 which also affects both business, consumers and residents live within the community where farm tourism is located.

There is significant difference in the assessment of detrimental impact of farm tourism in terms of economic when grouped to type of respondents since the computed $\mathrm{p}$ values is less than 0.05 level of significance. Therefore, in terms of assessment in detrimental impact of farm tourism in terms of economic varies when grouped to type of respondents, farm tourism employees' respondents had higher assessment in detrimental impact of farm tourism in terms of economic. It is enshrined in the study of Yamagishi, et al. (2021) that Filipinos viewed agricultural career has no future because it is less prioritized here in the Philippines.

There is significant difference in assessment in beneficial impact of farm tourism in terms of social when grouped according to civil status since the computed $\mathrm{p}$ values is less than 0.05 level of significance. Therefore, assessment in beneficial impact of farm tourism in terms of social varies when grouped to civil status. Most of the married respondents had higher assessment in the beneficial impact of farm tourism in Batangas province terms of social compared to single. According to Kara and Mkwizu (2020) married leisure visitors visited the 
nation for social reasons, according to the survey. Compared to singles, married ones choose to spend quality time with their children outside their comfort zone by participating in both physical and social leisure. In general, tourism not only brings individuals from various cultural backgrounds together, but it also allows them to interact and connect with one another.

There is significant difference in the assessment of beneficial and detrimental impact of farm tourism in terms of economic, social, cultural, and environmental when grouped to education since the computed $\mathrm{p}$ values are less than 0.05 level of significance. Thus, education affects the assessment in beneficial and detrimental impact of farm tourism in terms of economic, social, cultural, and environmental. Respondents who finished graduate studies had higher assessment in beneficial impact of farm tourism in terms of economic, social, cultural, and environmental and assessment in detrimental impact of farm tourism in terms of economic. Moreover, respondents who were vocational graduate had greater assessment in detrimental impact of farm tourism in terms of social, cultural, and environmental. It showed that the result from the gathered data that there is a significant difference in the detrimental impact of farm tourism in Batangas province when grouped according to education in terms of economic that the cost of living in the community has increased. Most respondents think that the cost of living in the neighborhood has risen significantly since they have noticed it in their everyday purchases of products and services. In addition, a lot of studies shows that Batangas province has been harmed by inflation because it is the Philippines' fastest expanding province.

On the contrary, the result from the gathered data showed that there is a significant difference in the beneficial impact of farm tourism in Batangas province when group according to education in terms of economic where Farm tourism raises the price of services because many people visit areas to learn about the culture, traditions, and food of the hosting country, local businesses profit the most from those visited the farm tourism. Local eateries, shopping centers, and businesses benefit greatly from the business in the nearby areas (Yehia, 2019). While the local government earned tax because local government units (LGUs) receive funding from local sources, as stated in National Tax Research Center (2021). Local sources include tax revenue from the real estate and business taxes, as well as non-tax revenues from fees and charges, receipts from government business activities, and earnings from asset sales.

There is also a significant difference in the detrimental impact of farm tourism in Batangas province when grouped according to education in terms of social where values of the youths were being distorted. The respondents believe that tourism has a negative impact when it comes to the volume of tourist arrivals in the area. The behavior was being influenced negatively by the tourist in different aspects. As previously said, tourism has had an impact on the locals' values, particularly among the youth. A shift in local attitudes toward visitors is one of the sociological repercussions of growing tourist numbers. The way communities view tourism's good and negative repercussions determine this transition. Locals' social carrying capacity restrictions, or their ability to bear changes as they occur, have resulted in the emergence of a negative attitude toward visitors (Szromek, Kruczek, \& Walas, 2019).

On the other hand, the results showed that there is a significant difference in the beneficial impact when group according to education in terms of social where respondent moderately agreed with lowest assessment when it comes to farm tourism contributing to the safety and security of the area. It may be observed by the respondent that Batangas is just like any other Philippine province in terms of safety, that they don't see any improvement in terms of safety and security service in the area. It is found that Batangas Police officers implemented a plan to avoid crime by keeping a strong presence in specific areas/jurisdictions. Technological components have been identified as the key contributor to the incidence of crime De Chavez, Panganiban, Galvero, Fondevilla and Escabel (2016).

Also, there is as significant difference in the beneficial and detrimental impact of farm tourism in Batangas province when grouped according to education in terms of cultural where respondents moderately agreed that the commercial demand of tourists causes changes in the style and forms of traditional arts and crafts and 
commercialized human relationships. Residents in the surrounding communities are forced to commercialize their human relationships with tourists to exist daily. When it comes to tourist's desire for traditional arts and crafts to be changed, they have been influenced to innovate because modernism has gone far and wide, and this is one of the key reasons why culture is quickly lost.

Traditional social life has changed significantly at some World Heritage sites because of the tourism industry's ongoing expansion, according to Zhuang, Yao, and Li (2019). Furthermore, many rural people's opinions have shifted irreversibly because of the increased reliance of many regions' economies on tourism. One example of these transformations is the impact of tourist growth and its economic efficiency on residents' traditional values, lifestyles, and interpersonal interactions in historic villages classified as WHSs. Furthermore, the result also showed that there is a significant difference in the beneficial impact when grouped according to education in terms of cultural where the cultural exchange between residents and tourists are valuable for the farm tourism. Respondents are undecided about the value of cultural exchange in farm tourism. Some tourists go to rural tourism to get away from their typical surroundings and to de-stress from a poisonous environment. One of the reasons why cultural interchange between tourists and locals seldom occurs.

Farm or agricultural tourism-based vacations in the country are becoming increasingly popular among tourists wishing to relax peacefully in nature. Farm tourism is a quick getaway to a place where you can unwind in nature and get away from the crowds. (Zbierska, 2020) There is as significant difference in the beneficial and detrimental impact of farm tourism in Batangas province when grouped according to education in terms of environmental where all the respondents did not agree on everything, but the most significant impact was that agricultural tourism increases competition for scarce resources like water and land, resulting in soil degradation, loss of wildlife habitats, and deterioration of landscape. It is observed may be by the residents that even farm tourism was concerned about the preservation of ecology but the abovementioned is not prioritized.

Lastly, results showed that there is a significant difference in the beneficial impact when group according to education in terms of environmental where the least assessment is farm tourism has improved the ecological environment of the community in many ways. However, the residents in Batangas Province moderately agreed that the ecological environment of Batangas province has already improved its because most of the farm tourism locations are almost near the urban areas where there are lots of smoke belching vehicles in the municipality of San Jose, Bauan, Alitagtag, Taal, Laurel, Mataas na Kahoy and Rosario. Some of its locations are near the factories like in Bauan. It is also assessed based on the answer that most of the respondents, specifically those who are in Graduate school or already acquired Advance studies that they are aware or well informed regarding the beneficial impacts and detrimental impacts of farm tourism in Batangas province. Furthermore, educational attainment was judged crucial when assessing agricultural supplies. This suggests that the responses to the degree attained by the respondents differ. People having a doctoral degree were shown to have a higher ranking. Those with a bachelor's degree and a vocational degree, on the other hand, lack appropriate knowledge and information about farm tourism (Lago, 2017).

There is significant difference in assessment of beneficial and detrimental impact of farm tourism in terms of economic, social, cultural, and environmental when grouped to location of farm tourism since the computed $\mathrm{p}$ values are less than 0.05 level of significance. Therefore, location of farm tourism affects the assessment in beneficial and detrimental impact of farm tourism in terms of economic, social, cultural, and environmental. Respondents who are from Taal, Batangas had higher assessment in beneficial impact of farm tourism in terms of economic, social, cultural, and environmental. Respondents who are from San Jose, Batangas had greater assessment in detrimental impact of farm tourism in terms of economic and social. Moreover, respondents who are from Rosario, Batangas had greater assessment in detrimental impact of farm tourism in terms of cultural and environmental.

The result showed that there is a significant difference in the detrimental impact of farm tourism in Batangas province in terms economic when grouped according to location of farm tourism that the cost of living in the 
community has increased. It is observed that the location has the respondents moderately agreed that the cost of living in the community has drastically increased because they felt it based on their daily basis in purchasing goods and services. Batangas province ranked second in the entire CALABARZON area in terms of quicker inflation rates in August 2021, with an increase of 1.5 percent index points (PSA, 2021).

The study showed that there is a significant difference in the detrimental impact in terms of social where this is a cause of value distortion among the youth. Moreover, farm tourism has influenced the values of residents, particularly the youth. A shift in local attitudes toward visitors is one of the sociological repercussions of growing tourist numbers., cultural and environmental. A shift in local attitudes toward visitors is one of the sociological repercussions of growing tourist numbers. The way communities view tourism's good and negative repercussions determine this transition. Locals' social carrying capacity restrictions, or their ability to bear changes as they occur, have resulted in the creation of a hostile attitude toward tourists (Szromek, et al., 2019). Furthermore, the study showed that there is a significant difference in the detrimental impact in terms of cultural where commercial demand of tourists causes changes in the style and forms of traditional arts and crafts due residents in the surrounding communities must monetize their human relationships with tourists to exist daily. When it comes to tourist desire for traditional arts and crafts to be changed, they have been influenced to innovate because modernism has gone far and wide, and this is one of the key reasons why culture is quickly lost. Traditional social life has changed significantly at some World Heritage sites because of the tourism industry's ongoing expansion, according to Zhuang, Yao, and Li (2019). Furthermore, many rural people's opinions have shifted irreversibly because of the increased reliance of many regions' economies on tourism.

Lastly it is also shown from the result of the study that there is a detrimental impact of farm tourism in Batangas province in terms of environmental where farm tourism brings increased competition for limited resources such as water and land, resulting in land degradation, loss of wildlife habitats and deterioration of scenery. The obvious aim of farm tourism is environmental preservation and promotion of rural tourism, which is defined as tourism that takes place in non-urbanized areas. These types of locales include national parks, woods, rural areas, and mountainous areas. Many farm tourism activities are focused on ecological and environmental preservation as part of agritourism to ensure that ecosystems, human populations, and the natural environment may be preserved. It combines agriculture and forestry, concentrates on cash crops while also improving soil quality and biodiversity, and broadens the range and quantity of agricultural products (Tseng, et al., 2019).

Given that Taal has a lot of tourism products to offer and services, the residents of the municipality are aware regarding the significance of tourism including farm tourisms in terms of economic, social, cultural, and environmental. On the contrary, the municipalities of Rosario and San Jose compared to Taal Batangas has a lesser tourism product and services to offer. These two municipalities are said to be rich in agricultural products but not related to tourism. This may be the reason why residents of the abovementioned municipalities are not aware on the significance of tourism or Farm tourism to be specific in terms of economic, social, cultural, and environmental.

\section{Conclusion and Recommendation}

From the gathered findings of the study, the following conclusions were drawn: Based on the findings of the study, majority of the respondents are Millennials which from ages 25-40 years old, male, single, high school graduate, local residents of the municipalities where farm tourism sites are located and majority of them are from the municipality with the greatest number of populations used in the study, which is Rosario, Batangas. The study showed that the beneficial impact of farm tourism in Batangas province is that it can provide jobs to the locals in terms of economics, infrastructures and other local services are maintained in terms of social, while in in terms of cultural, meeting guests has offered residents with life-enriching experiences and lastly, commitment to the preservation of the natural environment and the conservation of the community's wildlife in terms of environmental which most of the respondents agreed. 
Respondents moderately agreed in the detrimental impacts of Farm Tourism in Batangas province in terms of economic which it can increase the cost of living in the community, causes value distortion among youth in terms of social, and changes in the traditional arts and crafts added with the human relationship commercialization in terms of cultural impact and in contrary, majority of the respondents disagreed that farm tourism has a detrimental impact in terms of environmental. There is a significant difference in the detrimental impact of farm tourism in Batangas province when grouped according to Age in terms of economic, social, cultural, and environmental; same goes when group according to sex and types of respondents in terms of economic; and when grouped according to education and location of the respondents in terms of economic, social, cultural, and environmental. On the other hand, there is a significant difference in the beneficial impact when group according to civil status in terms of social and lastly, when group according to education and location of the respondent in terms of economic, social, cultural, and environmental.

Considering the findings and conclusions from this study, the following recommendations were endorsed. Since majority of the respondents finished high school which can possibly hinder farm tourism sustainability due to lack of education, the local government unit and farm tourism owners may offer corporate social responsibility specifically giving scholarships to students taking tourism management and agricultural courses which may become a potential employee in the future and to the present high school graduate employees to take related vocational courses that can contribute to the provinces' farm tourism growth. Farm tourism owner may strengthen the communication with different government agencies to seek help in the intensive promotional and marketing strategy of the local farm produce to maintain the benefits of farm tourism considering its impact in terms of economic, social, cultural, and environmental.

The Local Government Unit and Farm Tourism Organizations in the province may conduct awareness seminar as proposed in the action plan of this study with specific topic based on the result of the study regarding the detrimental impact such as cost of living in the community, importance of values among youth towards the tourist, human relationship commercialization and importance of cultural identity preservation and lastly, importance of environmental preservation anchored to the farm tourism sustainability. Farm tourism owner in collaboration with different related government agencies in the province such as Provincial Tourism/Department of Tourism together with the Tourism Promotion Board, Department of Agriculture and Department of Trade and Industry may help initiate programs to nearby community where farm tourism sites are located as proposed in the action plan focused to different tourists visiting the farm. Future researchers may conduct studies using different tourists as the primary respondents. They may also determine the impact of farm tourism based on the perception or assessment of both the tourists and farm owners or vice versa. They may also validate the information gathered in this study, and to develop or improved the proposed action plan based on their findings regarding farm tourism sustainability.

\section{References}

An, Y., Moon, J.-W., \& Norman, W. C. (2021). Investigating Residents'Attitudes towards Tourism Growth in Downtown Greenville, SC: The Effect of Demographic Variables. Sustainability. https://doi.org/10.3390/su13158474

Ani \& Cassola (2020). Transcending Barriers in Agriculture through Gender and Development. https://ap.fftc.org.tw/article/1872

Bhandari, P. (2021, February 15). An introduction to quantitative research. Scribber. https://www.scribbr.com/methodology/quantitative-research/

Bhatta, K., \& Ohe, Y. (2020). A review of quantitative studies in agritourism: The implications for developing countries. Tourism and Hospitality. https://doi.org/10.3390/tourhosp1010003

Buted, et. al. (2018). Effects of Importation to the Economic Development of Batangas Province, Philippines. Asia Pacific Journal of Academic Research in Social Sciences, 3, 43-50.

Chang, K.G., et. al. (2018, December 13). The impacts of tourism development in rural indigenous destinations: An investigation of the local residents' perception using choice modeling. Sustainability. 
https://doi.org/10.3390/su10124766

Cities and Municipalities Competitive Index (CMCI) of Batangas province. (2020). Ranking of Cities and Municipalities in terms of Population and Urbanization. https://cmci.dti.gov.ph/prov-profile.php?prov=Batangas\&year $=2020$

De Chavez, M. M., Panganiban, C. J., Galvero, R. A., Fondevilla, P. F., \& Escabel, E. B. Crime Demography in Batangas City: Basis for Improved Patrol Strategies. College of Criminology Research Journal. https://research.lpubatangas.edu.ph/wp-content/uploads/2019/02/CRIM-2016-005.pdf

Department of Trade and Industry (2017). The Philippines in Agribusiness Global Value Chains: Introduction. Policy Brief Series No. 2017-11. Retrieved from https://industry.gov.ph/wp-content/uploads/2017/11/ DTI-Policy-Brief-2017-11-The-Philippines-in-Agribusiness-Global-Value-Chains.pdf

Festijo, B. T., et.al. (2019). Benefits of Agritourism in Batangas Province. Asia Pacific J. of Education, Arts and Sciences, 6(3) http://apjeas.apjmr.com/wp-content/uploads/2019/08/APJEAS-2019-6.3-002.pdf

Gabor, M. T., (2016, June 05) Why Farm Tourism? Business Mirror. https://businessmirror.com.ph/2016/06/05/why-farm-tourism/

Kara, N. S., \& Mkwizu, K. H. (2020). Demographic factors and travel motivation among leisure tourists in Tanzania. International Hospitality Review, 34(1), 81-103. https://doi.org/10.1108/ihr-01-2020-0002

Kim, K. (2002). The effects of tourism impacts upon quality of life of residents in the community (pp. 236 - 244).. Virginia Polytechnic Institute and State University.

Lago, N. A. A. (2017). Tourism demand and agriculture supply: Basis for Agritourism Development in Quezon Province. Asia Pacific Journal of Multidisciplinary Research, 5(3), 1-9.

Leake, T. A. (2018). Millennial Effects on Tourism and Branding in Rural Destinations. University of Mississippi. eGrove. https://egrove.olemiss.edu/cgi/viewcontent.cgi?article=1921\&context=hon_thesis

National Anti-Poverty Commission (2019, January 24). Statement: Organic Farming is the sustainable solution to uplift the lives of the farmers. Retrieved from https://napc.gov.ph/basic-sectors/farmers-and-landless-rural-workers

National Tax Research Center. (2021). Local Taxes. https://ntrc.gov.ph/images/Publications/guide-to-philippine-taxes-2016/local-taxes.pdf

Ochave, R.M.D., (2020, July 16). DoT ties up with FAO to promote sustainable farm tourism in PHL. Business World. www.bworldonline.com/dot-ties-up-with-fao-to-promote-sustainable-farm-tourism-in-phl/

Petrovic, M. D., Blešić, I., Vujko, A., \& Gajić, T. (2017). The role of agritourism's impact on the local community in a transitional society: A report from Serbia. Transylvanian Review of Administrative Sciences, 13(50), 146-163. https://doi.org/10.24193/tras.2017.0009

Philippine Statistic Authority (2021). CALABARZON's Inflation Rate climbed to 6.0 percent in August 2021. http://rsso04a.psa.gov.ph/cpi

Philippine Statistic Authority (2021, March 16). Marriages in Batangas 2019 (Final Result). http://rsso04a.psa.gov.ph/article/marriages-batangas-2019-final-result

Province of Batangas Official Website. (2021). History. https://www.batangas.gov.ph/portal/history/

Rebollo, H. P. M. (2018). A structural model of millennial tourist behavior towards tourism in Davao Region. Journal of Advances in Humanities and Social Sciences. http://www.tafpublications.com/gip_content/paper/Jahss-4.1.3.pdf

Retnowulandari, W. (2018). A review of the "head of the family concept from the family law, gender perspective. SHS Web of Conferences. https://doi.org/10.1051/shsconf/20185402008

Sharmin, F., Sultan, M. T., Badulescu, A., Bac, D. P., \& Li, B. (2020). Millennial Tourists' Environmentally Sustainable Behavior Towards a Natural Protected Area: An Integrative Framework. Sustainability. https://doi.org/10.3390/su12208545

Shellhouse, Spratley and Suarez (2020). Influencing Factors on the Pursuit of Graduate Degrees in Agricultural Social Sciences. Journal of Agricultural Education. https://doi.org/10.5032/jae.2020.01074

Social Farming Ireland (2019). Benefits for Participants. https://www.socialfarmingireland.ie/a-social-farming-day/benefits/ 
Catapang, Efren S., Jr., \& Ylagan, A. D.

Szromek, A. R., Kruczek, Z., \& Walas, B. (2019). The Attitude of Tourist Destination Residents towards the Effects of Over tourism - Kraków Case Study. Sustainability. https://doi.org/10.3390/su12010228

Taloza, B.C.R. (2020). Tourism in the Heritage City of Vigan: Basis for Sustainable Development. P. 99 - 107.

Tseng, et. al. (2019). Sustainable Agritourism in Thailand: Modeling Business Performance and Environmental Sustainability under Uncertainty. Sustainability. https://doi.org/10.3390/su11154087

Yamagishi, K., Gantalao, C., \& Ocampo, L. (2021, March 12). The future of farm tourism in the Philippines: challenges, strategies, and insights. Journal of Tourism Futures. https://doi.org/10.3390/su11030812

Yehia, Y. (2019, March 26). The Importance of Tourism on Economies and Businesses. Global Edge. https://globaledge.msu.edu/blog/post/55748/the-importance-of-tourism-on-economies-a

Zbierska, M. M. W., et. al. (2020, September 08). Agritourism in the Era of the Coronavirus (COVID-19): A Rapid Assessment from Poland. https://doi.org/10.3390/agriculture10090397

Zhuang, X., Yao, Y., \& Li, J. (2019). Sociocultural Impacts of Tourism on Residents of World Cultural Heritage Sites in China. Sustainability. https://doi.org/10.3390/su11030840 